\title{
RESPONSE TO A SIMPLE VASCULAR TEST FOR WORKERS CHRONICALLY EXPOSED TO COLD
}

\author{
By \\ Fahmy, F.C. and Kamel, A. \\ From \\ Department of Occupational Health, High Institute of Public Health, \\ Alexandria University.
}

\begin{abstract}
:
Objective: The present study was designed to investigate local and systemic responses to cold provocation testing as a simple vascular test for workers chronically exposed to cold. Materials and Methods: The study included 22 male workers from cold storage facilities and a matched non-exposed control group of 20 subjects. All participants were non-hypertensives and free from diabetes and cardiovascular diseases. They were subjected to a questionnaire, resting blood pressure measurement, cold provocation testing and Doppler radial systolic blood pressure measurement before and after cold provocation.
\end{abstract}

Results: Hypertensive response was observed more significantly among cold exposed workers than controls $(\mathrm{p}=0.003)$. Blanching response to cold was not significantly different between exposed and control groups. Coupled response was significantly higher among cold exposed workers than controls $(p=0,006)$ and it was independently determined by duration of exposure $(\mathrm{p}=0.001)$.

Conclusion: It seems that coupled response to cold provocation testing is a simple outcome measure for screening chronically exposed workers to cold.

Key words: Workers exposed to cold - Vascular test - Cold provocation - Blanching response _ Hypertensive response.

Abbreviations: DBP, diastolic blood pressure; RSBP, radial systolic blood pressure; SBP, systolic blood pressure. 


\section{Introduction:}

Since long time, it is known that exposure to cold leads to vasoconstriction of peripheral circulation causing frostbite and its complication especially in extremities (Lewis, 1931). Reynaud's phenomenon is an episodic vascular disorder induced by cold temperature and characterized by white, blue and red discoloration of the fingers and toes. It may affect up to $20 \%$ of general population either as primary condition or secondary to collagenic diseases (Wigley, 2002).

Boster et al. (1995), stated that it is very difficult to confirm Reynaud's phenomenon during office examination because of rapid disappearance of attacks. Therefore, laboratory simulation experiments are needed for cold exposed workers or other situations. For example, cold provocation testing is a good tool with different outcome measures including finger skin temperature, finger systolic blood pressure, finger skin blood perfusion by laser Doppler and simply the blanching response of fingers (Fujuvara et al., 2008 and Miyai et al., 2005).

O'Brien et al. (2000), observed that the vascular responses associated with cold exposure seem to extend beyond peripheral blood vessels. Skin temperature reduction alone may be a sufficient stimulus for in- creased vasoconstrictor response, but core temperature reduction appears necessary to enhance sympathetic and rennin angiotensin system during cold exposure. Elevations in blood pressure and even cardiac affection were studied in relation to climatic cold exposure or laboratory cold pressor testing (Rostrup,1994). Blood pressure elevations in response to cold exposure may be so minor or exaggerated to more than $10 \mathrm{mmHg}$ as a short term reaction and need sensitive method such as continuous wave Doppler for accurate measurement of the systolic blood pressure (Lanzer and Topol, 2002).

According to Gavhed and Holmer (1992), it is reported that the occupational exposure to cold is currently increasing. Many workers spend several daily hours exposed to cold in their work environment. Cold storage facilities, meat-packing houses, freezer plants, ice makers and liquefied gas workers are some examples of these jobs. There is no clear specific diagnostic tools for health surveillance of workers exposed to cold in periodic medical examination and most studies utilize general nonspecific parameters.

The present study was designed to investigate the local and systemic responses to cold provocation testing as a simple vascular test among workers chronically exposed to cold. 


\section{Subjects and Methods:}

The present study included 22 male workers with history of chronic exposure to cold. They were randomly selected from attendants to periodic medical examination at Occupation Health Center, High Institute of Public Health, WHO, collaborating center. They are working in cold storage facilities and they are exposed to about $4^{\circ} \mathrm{C}$ ambient temperature for about 4 hours daily as obtained from their job records.

The included workers had normal resting blood pressure measurement and gave no history of hypertension, diabetes mellitus, coronary artery disease, peripheral vascular insufficiency or collagenic disorders that may bias the results. A matched group of 20 male healthy subjects occupying administrative jobs not exposed to cold was included as a control group. All participants were subjected to a questionnaire about personal date, smoking habits, medical conditions and occupational history. Resting systolic and diastolic blood pressure was measured by the standard methods (ESH and ESC, 2007).

Cold provocation test was done by immersion of both hands in cold water at $10^{\circ} \mathrm{C}$ for 5 minutes according to Lascar and Harada (2005). The local reaction was assessed by positive blanching response of fingers.
In case of positive response the blanched phalanges of the more affected hand was counted as a score of 14 (Bovenzi, 1998). This test was done after ethical consideration and having a consent from each participant.

Radial Systolic blood pressure (RSBP) was measured by a portable vascular Doppler (Seward, UK) and a standard sphygmomanometer to increase sensitivity for determination of the first Kortokoff sound according to the manual of operating instruction. Measurements were recorded before (RSBP1) and after (RSBP2) the cold immersion test. If the difference between both measurements was $>10 \mathrm{mmHg}$ hypertensive response was considered. Those who showed both blanching and hypertensive responses were considered as having a coupled response.

Statistical analysis of the data was computed using the SPSS package 15 . Chi-square and student t-tests were used for comparison between proportions and quantitative variables respectively. Logistic regression models were constructed to test for variables independently affecting the dependent one after adjustment for confounders. Significance was considered at $p$ level 0.05 . 


\section{Results:}

The mean age of cold exposed workers and control subjects were $36.3 \pm 7.98$ years and $36.3 \pm 7.34$ years respectively with no statistically significant difference. The mean duration of exposure among cold exposed workers was $13.5 \pm 6.28$ years. Only three cases of the exposed workers gave history of attacks of Raynaud's phenomenon.

Table 1 showed that, there were no statistically significant differences for the measurements of resting SBP, DBP and Doppler RSBP1 before cold immersion test. The Doppler measurement RSBP2 after cold immersion test as well as the difference between after and before values were significantly higher among exposed workers in comparison to controls ( $\mathrm{p}=0.016$ and 0.001 respectively).

Table 2 revealed that no statistically significant differences between exposed workers and controls existed for smoking, smoking index, blanching response and blanched phalanges . Both hypertensive and coupled responses were statistically significantly higher among exposed workers than controls ( $\mathrm{P}=0.003$ and 0.006 respectively).

Table 3 presented the results of logistic regression analyses revealing that duration of exposure was the only independent determinate in the model of hypertensive response, as well as the model of coupled response ( $\mathrm{p}=0.000$ and 0.001 respectively) . In the first model, the blanched response was about to approach significance.

Table 4 demonstrated that the mean count of blanched phalanges in cold water immersion test was significantly higher among those with hypertensive response than those with no hypertensive response $(\mathrm{p}=0.002)$. 
Table 1 : Resting and Doppler measurements of blood pressure

\begin{tabular}{|c|c|c|c|c|c|c|}
\hline \multirow{3}{*}{ Measurements } & \multirow{2}{*}{\multicolumn{2}{|c|}{$\begin{array}{c}\text { Exposed Workers } \\
(\mathrm{n}=22)\end{array}$}} & \multirow{2}{*}{\multicolumn{2}{|c|}{$\begin{array}{c}\text { Control Subjects } \\
(\mathrm{n}=20)\end{array}$}} & \multirow{3}{*}{$\mathrm{t}$} & \multirow{3}{*}{$\mathrm{P}$} \\
\hline & & & & & & \\
\hline & Mean & S.D & Mean & S.D & & \\
\hline $\begin{array}{l}\text { SBP } \\
\quad(\mathrm{mmHg})\end{array}$ & 121.6 & 8.22 & 121.3 & 7.93 & 0.019 & 0.892 \\
\hline $\begin{array}{l}\text { DBP } \\
\qquad(\mathrm{mmHg})\end{array}$ & 77.1 & 6.67 & 74.8 & 6.17 & 1.333 & 0.255 \\
\hline $\begin{array}{l}\operatorname{RSBP}_{1} \\
\quad(\mathrm{mmHg})\end{array}$ & 125 & 9.26 & 122.8 & 8.35 & 0.679 & 0.415 \\
\hline $\begin{array}{l}\mathrm{RSBP}_{2} \\
\quad(\mathrm{mmHg})\end{array}$ & 139.8 & 13.41 & 129.8 & 12.19 & 2.38 & $0.016^{*}$ \\
\hline $\begin{array}{r}\mathrm{RSBP}_{2}-\mathrm{RSBP}_{1} \\
(\mathrm{mmHg})\end{array}$ & 14.8 & 7.93 & 7.0 & 5.71 & 4.024 & $0.001^{*}$ \\
\hline
\end{tabular}

*Significant at level 0.05 
Table 2 :Smoking and the examined vascular responses.

\begin{tabular}{|c|c|c|c|c|}
\hline Variables & $\begin{array}{c}\text { Exposed } \\
\text { Workers }(n=20)\end{array}$ & $\begin{array}{c}\text { Control } \\
\text { Subjects }(n=22)\end{array}$ & $X^{2}$ & $\mathrm{p}$ \\
\hline Smoking & $\begin{array}{c}10 \\
(45.5)\end{array}$ & $\begin{array}{c}8 \\
(40.0)\end{array}$ & 0.127 & 0.483 \\
\hline Smoking Index & 150.5 & 137.5 & $0.050^{@}$ & 0.824 \\
\hline (Cigarette/day. year) (S.D.) & (181.14) & (193.90) & & \\
\hline Blanching response & $\begin{array}{c}7 \\
(31.8)\end{array}$ & $\begin{array}{c}3 \\
(15.0)\end{array}$ & 1.633 & 0.181 \\
\hline Blanched phalanges & 1.7 & 0.7 & $1.284^{@}$ & 0.139 \\
\hline (Score: 0-14) & $(2.76)$ & $(1.66)$ & & \\
\hline $\begin{array}{r}\text { Hypertensive response no. } \\
(\%)\end{array}$ & $\begin{array}{c}12 \\
(54.5)\end{array}$ & $\begin{array}{c}2 \\
(10.0)\end{array}$ & 9.35 & $0.003^{*}$ \\
\hline Coupled response & $\begin{array}{c}7 \\
(31.8)\end{array}$ & $\begin{array}{c}0 \\
(0.0)\end{array}$ & 7.636 & $0.006^{*}$ \\
\hline
\end{tabular}

*Significant at level 0.05 .

@t-test. 
Table 3: Logistic regression models with hypertensive and coupled responses as dependent variables

\begin{tabular}{|l|c|c|c|c|c|}
\hline \multicolumn{1}{|c|}{ Model } & B & SE & Beta & t & P \\
\hline Hypertensive response model: & & & & & \\
\hline Duration of exposure (years) & 0.031 & 0.007 & 0.528 & 4.233 & $0.000^{*}$ \\
\hline SBP (mmHg) & 0.007 & 0.007 & 0.12 & 0.976 & 0.335 \\
\hline Blanching response (no=0 \& yes=1) & 0.272 & 0.14 & 0.226 & 1.99 & 0.059 \\
\hline Coupled response model: & & & & & \\
\hline Duration of exposure (year) & 0.022 & 0.006 & 0.482 & 3.437 & $0.001^{*}$ \\
\hline Smoking index (cigarettes/day. year) & 0 & 0 & 0.053 & 0.354 & 0.725 \\
\hline SBP (mmHg) & 0.006 & 0.007 & 0.125 & 0.823 & 0.416 \\
\hline
\end{tabular}

*Significant at level 0.05

Table 4: Blanched phalanges count according to hypertensive response.

\begin{tabular}{|c|c|c|}
\hline Blanched phalanges count & $\begin{array}{c}\text { Hypertensive response } \\
(\mathbf{n = 1 4})\end{array}$ & $\begin{array}{c}\text { No hypertensive response } \\
(\mathbf{n = 2 8})\end{array}$ \\
\hline Range & $0-8$ & $0-6$ \\
\hline Mean & 2.71 & 0.46 \\
\hline S.D. & 3.07 & 1.43 \\
\hline
\end{tabular}

\section{t. 4.63}

$p=0.002$ 


\section{Discussion:}

The present study examined different responses for cold water immersion test among workers chronically exposed to cold in a laboratory simulation model as a trial to indentify the susceptible individuals .

The blanching response of fingers indicates an exaggerated local response of vasoconstriction. Unexpectedly , there was no significant difference between exposed workers and controls in this response expressed either qualitatively or quantitatively in terms of blanched phalanges count. This test had shown reproducibility to other occupational exposures affecting peripheral blood vessels such as vibration (Fahmy et al., 2000). Wigley (2002), reported that cold induced severe local vascular reactions were associated with acute exposure to extremely low temperature rather than chronic exposure to the current level. In chronic exposure, the main central body heat protects extremities. It could be assumed that chronic repeated exposure to reasonable level of cold may produce a form of acclimatization ameliorating peripheral vascular responses.

On the other hand, hypertensive response to laboratory cold exposure was significantly observed among exposed workers by qualitative and quantitative measures in the present study. This response was independently determined by duration of exposure to cold. Also, the blanching response was approaching to be a significant predictor for the hypertensive response. This significance limitation may be due to the small sample size . However, the blanched phalanges count was significantly high among those with hypertensive response. These findings may be explained by a vasospastic process in which the local response is a part of expanded mechanism beyond local effects. This is going with the recent experimental studies by Chen and Sun (2006), who observed an increase in endotheline-1 with up-regulation of its receptors in a pathway inducing potent vasoconstrictor response to cold exposure both locally and systemically. Kim et al. (2003), found that cold exposure was a risk factor for hypertension among workers in refrigeration industries. Moreover, cardiovascular mortality was reported to increase due to cold exposure in winter time (BakerBlocker, 1982).

All cases with coupled response were chronically exposed to cold in the current study. Duration of exposure kept to be the independent determinant of this coupled response even after adjustment for confounders that may affect vascular reactivity mainly smoking and SBP. It seems that 
identification of cases with both peripheral and hypertensive responses simultaneously is a reasonable estimate for whole body vascular response among cold exposed workers.

\section{Conclusion and Recommendations:}

It seems that coupled response to cold provocation is a reasonable simple test to identify susceptible workers for vascular reactions due to chronic exposure to cold.

It is recommended to screen workers chronically exposed to cold in periodic medical examination by cold provocation testing looking for coupled response. Positive cases should receive close observation and proper preventive measures with frequent blood pressure measurements.

\section{References:}

1. Baker-Blocker, A. (1982). "Winter weather and cardiovascular mortality in Minnapolis-St. Paul.” Am J Public Health. 72:261-265.

2. Boster, M.B., Maricq, H.R. and Leff, R.L. (1995). "Office evaluation and treatment of Raynaud's phenomenon." Cleve Clin J Med. 62(1): 51-61.

3. Bovenzi, M. (1998). "Vibration-induced white finger and cold response of digital arterial vessels in occupational groups with various patterns of exposure to hand-transmitted vibration." Scand J Work Environ Health. 24(2): 138-144.

4. Chen, G.F. and Sun, Z. (2006). "Effects of chronic cold exposure on the endothelin system.” J Appl Physiol. 100: 1719-1726.
5. ESH and ESC. (2007). The Task Force for Management of Arterial Hypertension of the European Society of Hypertension and of the European Society of Cardiology 2007 Guideline for the management of Arterial Hypertension. Eur Heart J. doi: 10.1093/eurheartj/ehm236.

6. Fahmy, F.C., Mansour, T.A., Abbas, F., Moselhi, M. and Osman, H. (2000). "Neurovascular changes among workers exposed to whole body vibration." Bulletin of High Institute of Public Health. 30(4): 771-782.

7. Fujuvara, Y., Yoshino, S. and Nasu, Y. (2008). "Simultaneous observation of zero-value of FSBP\% and Raynaud's phenomenon during cold provocation in vibration syndrome." J Occup Health. 50: 75-8.

8. Gavhed, D. and Holmer, I. (1992). "Work in the cold, clothing, heat balance and physiologic effects." Arbete Och Halsa, Solna. 32. (English Abstract)

9. Lanzer, P. and Topol, E.J. (2002). Panvascular Medicine Intergrated Clinical Management. Springer. Verlag Berlin Heidelberg, Germany.

10. Laskar, M.S. and Harada, N. (2005). "Different conditions of cold water immersion test for diagnosing hand-arm vibration syndrome." Environ Health Prev Med. 10: 351-359.

11. Lewis, T. (1931). "Observations upon the reactions of the vessels of the human skin to cold." Heart. 15:385.

12. Kim, J.Y., Jung, K.Y., Hong, Y.S., Kim, J.I., Jang, T. and Kim, J.M. (2003). "The relationship between cold exposure and hypertension." J Occup Health. 45: 300-306.

13. Miyai, N., Terada, K., Sakaguchi, S., Minami, Y., Tomura, T. Yamamoto, H. Tomida K. and 
Miyashita, K. (2005). "Preliminary study on the assessment of peripheral vascular response to cold provocation in workers exposed to handarm vibration using laser Doppler perfusion imager.” Indust Health. 43:548-555.

14. O’Brien, C., Young, A.J., Lee, D.T., Shitzer, A., Sawka, M.N. and Pandolf, K.B. (2000). "Role of core temperature as a stimulus for cold ac- climation during repeated immersion in $20^{\circ} \mathrm{C}$ water.” J Appl Physiol. 89:242-250.

15. Rostrup, M., Smith, G., Bjornstad, H., Werstheim, A., Stokland, O. and Eide, I. (1994). "Left ventricular mass and cardiovascular reactivity in young men. Hypertension.” 23(Suppl I): I168-171.

16. Wigley, F.M. (2002). "Raynaud's phenomenon.” New Engl J Med. 347(13): 1001-1008. 